\title{
Visual acuity improvements after implantation of toric intraocular lenses in cataract patients with astigmatism: a systematic review
}

\author{
Blaise Agresta ${ }^{1}$, Michael C Knorz ${ }^{2^{*}}$, Christina Donatti ${ }^{*}$ and Daniel Jackson ${ }^{3^{*}}$
}

\begin{abstract}
Background: Cataracts are a common and significant cause of visual impairment globally. We aimed to evaluate uncorrected distance visual acuity (UDVA) as an outcome in treating astigmatic cataract patients to assist clinicians or ophthalmologists in their decision making process regarding available interventions.

Methods: Medline, Embase and Evidence Based Reviews were systematically reviewed to identify relevant studies reporting changes in UDVA, UIVA and UNVA after cataract surgery in presbyopic patients. Strict inclusion/exclusion criteria were used to exclude any non-relevant studies. Relevant outcomes (UDVA, UIVA and UNVA) were identified from the studies retrieved through the systematic review process.

Results: The systematic review identified 11 studies which reported UCVA. All 11 studies reported UDVA. Four brands of toric intraocular lenses (IOLs) were reported in these studies. All studies identified in the literature search reported improvements in UDVA following surgical implant of a toric IOL. The largest improvements in VA were reported using the Human Optics MicroSil toric IOL (0.74 LogMAR, UDVA) and the smallest improvements were also reported using the Human Optics MicroSil toric IOL (0.23 LogMAR, UDVA) in a different study.

Conclusions: The results of this systematic review showed the aggregate of studies reporting a beneficial increase in UDVA with the use of toric IOLs in cataract patients with astigmatism.

Keywords: Astigmatism, Toric, Intraocular lenses, Uncorrected distance visual acuity, Uncorrected near visual acuity, Visual acuity, Systematic review, Cataracts
\end{abstract}

\section{Background}

The main cause of the formation of cataracts is age, but can also be ocular and systemic diseases (diabetes and uveitis), systemic medications (steroids and phenothiazines), trauma, ionizing radiation (X-ray and UV light), congenital diseases and inherited abnormalities (myotonic dystrophy, Marfan's syndrome, Lowe's syndrome, rubella) [1].

Cataracts are a common and significant cause of visual impairment globally. Cataract surgery is one of the most

\footnotetext{
*Correspondence: knorz@eyes.de; cdonatti@au.imshealth.com; Daniel. Jackson@AlconLabs.com

'Health Economics and Outcomes Research, IMS Health, London, UK ${ }^{2}$ FreeVis LASIK Center, Medical University of Mannheim, Mannheim, Germany ${ }^{3}$ Market Access and Reimbursement, Alcon Laboratories, Inc, Cointrin, Switzerland
}

(c) 2012 Agresta et al.; licensee BioMed Central Ltd. This is an Open Access article distributed under the terms of the Creative Commons Attribution License (http://creativecommons.org/licenses/by/2.0), which permits unrestricted use, distribution, and reproduction in any medium, provided the original work is properly cited.

commonly performed surgeries in the United Kingdom (UK) National Health Service (NHS). In the UK, $10 \%$ of persons aged 65 years and over have received cataract surgery and $30 \%$ of this population ( $\geq 65$ years) have been found to have a visually impairing cataract in one or both eyes [2]. The prevalence of cataract eye surgery increases with age, from $16 \%$ in the 65 to 69 age group to $71 \%$ in those aged 85 years or more and tends to affect women more than men. In the UK it is estimated that 2.4 million people aged 65 or older have a visually impairing cataract in one or both eyes and a further 225,000 new cases are predicted annually [3].

Astigmatism occurs when the patient's cornea is steeper in the vertical axis (with-the-rule astigmatism) or in the horizontal axis (against-the-rule astigmatism) [4] when the principal meridians are perpendicular. A third 
type of regular astigmatism, oblique astigmatism, occurs when the steepest curve lies between $120-150^{\circ}$ and $30-$ $60^{\circ}$. When replacing a lens during cataract surgery, astigmatism can either be corrected by prescription glasses, contact lenses, corneal relaxing incisions, astigmatic keratotomies, limbal relaxing incisions, excimer laser ablation, and toric IOL implantation.

Astigmatism and cataracts reduce the quality of life of a patient $[5,6]$. The use of a toric intraocular lens (toric IOL) is designed to replace the cataractous lens of an eye and to correct the corneal astigmatism. Thus if toric IOLs are safe and efficient, an increase in quality of life should be observed in cataract patients with astigmatism. This increase in quality of life would not have been as significant had only cataracts or astigmatism alone been treated in this patient population.

This systematic review attempts to identify and describe published literature reporting the postoperative UDVA, UIVA, and UNVA outcomes in patients undergoing cataract surgery with astigmatism and to show how close patients can achieve normal vision with the use of all toric IOLs.

\section{Results}

\section{Results of the systematic review}

The systematic review identified 11 studies that measured uncorrected visual acuity (Figure 1). Initially, UNVA and UIVA were also included in the analysis, but no studies were identified that reported UNVA or UIVA. Of the 11 studies that reported UDVA, 2 randomised controlled trials were identified, 7 observational studies, 1 prospective cohort study, and 1 retrospective observational. Using the Oxford centre for evidence based medicine-grades of evidence, 9 studies were classified as Level IIIb, and two studies categorized as Ib. A range of different outcome measurement units were reported, including using the decimal of the Snellen measurement, and the logarithm of the minimal angle of resolution (LogMAR).

Four brands of MIOLs were identified in these studies. These brands were Human optic MicroSil (6116TU), Rayner T-Flex (623T), AcrySof Toric (SN60T3, SN60T4, SN60T5) and Staar Toric (AA4203T).

This analysis showed gains in improvement for UDVA (Table 1). Post-operative UDVA values were closer to a normal sight score (20/20 Snellen) in 4 models of toric IOLs tested across the 11 studies.

Outcomes associated with astigmatism are reported in Table 2. When reported within the 11 identified studies, changes in refractive sphere, spherical equivalent, refractive astigmatism and keratometric astigmatism along with the mean age of the patients and the surgical incision used to implant the toric IOLs are shown.

The greatest changes in refractive sphere were reported by De Silva using the Human Optic MicroSil toric IOL with a change of 2.71. Reported pre/postoperative differences in spherical equivalent changes were also greatest in the De Silva study (an adjustment of 1.89). Entabi reported the greatest difference in refractive astigmatism (an adjustment of 2.4), using the Rayner T-Flex toric IOL, and Kersey reported the greatest change in keratometric astigmatism (an adjustment of 7.85) using the Human Optics MicroSil toric IOL.

The reported surgically induced astigmatism (SIA), rotational stability and if additional surgery was needed within the identified studies are shown in Table 3.

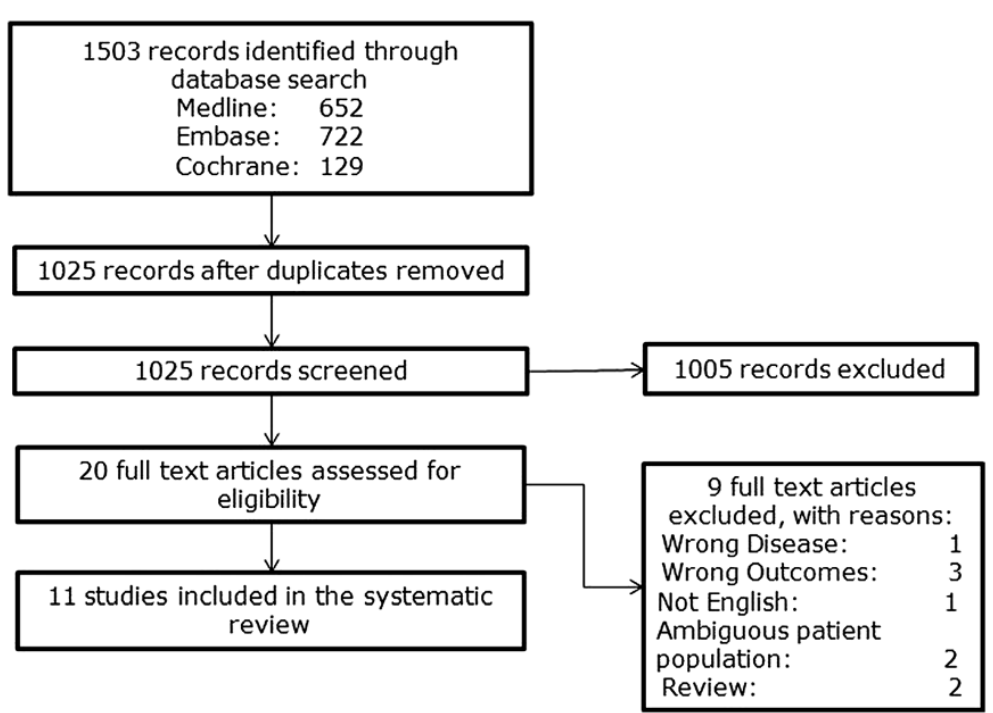

Figure 1 QUROUM chart describing inclusion and exclusion of studies included in this systematic review. 
Table 1 Results of the systematic review

\begin{tabular}{|c|c|c|c|c|c|c|c|}
\hline \multirow[t]{2}{*}{ Author } & \multirow[t]{2}{*}{ Study Type (Grade) } & \multirow[t]{2}{*}{ Lens } & \multirow[t]{2}{*}{ Unit Measurement } & \multirow{2}{*}{$\begin{array}{l}\mathrm{N} \\
\text { (eyes) }\end{array}$} & \multicolumn{3}{|c|}{ Uncorrected Distance Visual Acuity } \\
\hline & & & & & Preoperative & Postoperative & $\mathbf{P}$ \\
\hline De Silva (2006) [7] & Observational (Illb) & $\begin{array}{l}\text { Human Optics } \\
\text { MicroSil 6116TU }\end{array}$ & LogMAR-6 months & 21 & $0.55 \pm 0.34$ & $0.32 \pm 0.24$ & NR \\
\hline Entabi (2011) [8] & Observational (IIb) & Rayner T-Flex 623T & LogMAR-4 months & 33 & - & $0.28 \pm 0.23$ & NR \\
\hline Kersey (2007) [9] & Observational (llb) & $\begin{array}{l}\text { Human Optics } \\
\text { MicroSil 6116TU }\end{array}$ & LogMAR-9-19 months & 7 & $1.31 \pm 0.65$ & $0.39 \pm 1.15$ & NR \\
\hline Kim (2010) [10] & Observational (Illb) & AcrySof Toric & $\begin{array}{l}\text { LogMAR-13.3 months } \\
\text { (mean) }\end{array}$ & 30 & $0.87 \pm 0.67$ & $0.33 \pm 0.18$ & $<0.05$ \\
\hline Koshy (2010) [11] & Observational (Ilb) & AcrySof Toric SN60TT & LogMAR-6 months & 30 & - & 0.2 & $N R$ \\
\hline Lane (2009) [12] & Prospective (IIb) & AcrySof Toric & LogMAR-6 months & 40 & - & -0.07 & NR \\
\hline Leyland (2001) [13] & Observational (Ilb) & Staar Toric & LogMAR-8 weeks & 22 & $1.45 \pm 0.64$ & $0.27 \pm 0.25$ & NR \\
\hline Mendicute (2009) [14] & $\mathrm{RCT}(\mathrm{Ib})$ & $\begin{array}{l}\text { AcrySof Toric SN60T3, } \\
\text { SN60T4, SN60T5 }\end{array}$ & LogMAR-3 months & 40 & - & $0.11 \pm 0.15$ & NR \\
\hline Mendicute (2008) [15] & Observational (Illb) & $\begin{array}{l}\text { AcrySof Toric SN60T3, } \\
\text { SN60T4, SN60T5 }\end{array}$ & LogMAR-3 months & 30 & - & $0.16 \pm 0.18$ & NR \\
\hline Mingo-Botin (2010) [16] & $\mathrm{RCT}(\mathrm{lb})$ & AcrySof Toric & LogMAR-3 months & 40 & $0.72 \pm 0.26$ & $0.13 \pm 0.10$ & $N R$ \\
\hline Ruhswurm (2000) [17] & $\begin{array}{l}\text { Retrospective } \\
\text { observational (Ilb) }\end{array}$ & Staar Toric AA4203T & Decimal-3-62.8 months & 37 & - & $\begin{array}{l}0.61 \pm 0.29 \\
(0.21 \text { LogMAR) }\end{array}$ & NR \\
\hline
\end{tabular}

NR, Not reported.

\section{Outcomes of the systematic review}

The greatest increase in VA was reported by Kersey (2007), investigating the efficacy of the Human Optics MicroSil [9] with an increase of 0.92 LogMAR in UDVA. The smallest improvements in VA were reported by De Silva (2006). UDVA increased by only 0.23 LogMAR [7].

Of the patient study groups that were identified in the systematic search, the prospective study by Lane (2009) reported the mean VA with the closest value to normal VA (20/20) when measuring UDVA [12] with a postoperative UDVA of -0.07 LogMAR [12].

The trial by Kersey (2007), an observational study measuring the VA in the Human Optics MicroSil toric IOL measured the least gain in UDVA with a mean postoperative result of $0.39 \operatorname{LogMAR}$ [9]. It should be noted that the population in this trial also had the largest variation compared with other identified studies probably due to the small patient population $(\mathrm{N}=7)$. This population also had the largest mean degree of astigmatism $\left(10.12^{\circ}\right)$, which also allocates a smaller error accepted during the toric IOL positioning. This again was an outlier, with the highest reported mean corneal astigmatism after the Kersey trial, was reported by De Silva (2006), with a mean of 3.08.

\section{Methods}

\section{Systematic search}

The systematic review was conducted to evaluate the efficacy of toric IOLs in astigmatic cataract patients. Databases used in the search included: Medline, Medline In-Process (from 1948 to present), Embase (from
1988 to 2011) and Evidence Based Reviews were accessed via the OVID platform to search for relevant studies. The search terms used in search included: lens diseases, cataract, aphakia, cataract extraction, toric, lens implantation, lenses-intraocular, and astigmatism (see Additional file 1: Appendix A for full search results). An analysis of how the individual studies identified in the literature search were excluded was achieved using the QUORUM (Quality of Reporting of Meta-analyses) chart (Figure 1). Inclusion/exclusion criteria were used to systematically exclude any studies that were not relevant for the review. Accommodative lenses were not the focus of this review, and were excluded from the search. Studies that published results in a language other than English were also excluded. Data extraction was completed using a template created in Microsoft Excel. Data was extracted directly from the information reported in the published journal articles. Demographic data and study details (number of patients, study time length, patient population, interventions, comparators) and study outcomes were extracted. Baseline characteristics and the severity of the astigmatisms within the patient populations were also extracted. The Oxford Center for Evidence-based Medicine-Grades of Evidence [18] was used to grade the identified studies.

\section{Outcomes reviewed}

This analysis focused on UDVA. UIVA, and UNVA were initially included in the analysis. The safety of toric IOLs and the change in quality of life due to toric IOLs were not analysed in this review. 
Table 2 Astigmatic outcomes reported in studies identified in the systematic review

\begin{tabular}{|c|c|c|c|c|c|c|c|c|c|c|}
\hline \multirow[t]{2}{*}{ Author } & \multirow[t]{2}{*}{ Mean age } & \multirow[t]{2}{*}{ Incision } & \multicolumn{2}{|c|}{ Refractive Sphere } & \multicolumn{2}{|c|}{ Spherical Equivalent } & \multicolumn{2}{|c|}{ Refractive Astigmatism } & \multicolumn{2}{|c|}{ Keratometric Astigmatism } \\
\hline & & & $\begin{array}{l}\text { Pre } \\
\text { operative }\end{array}$ & $\begin{array}{l}\text { Post } \\
\text { operative }\end{array}$ & $\begin{array}{l}\text { Pre } \\
\text { operative }\end{array}$ & $\begin{array}{l}\text { Post } \\
\text { operative }\end{array}$ & $\begin{array}{l}\text { Pre } \\
\text { operative }\end{array}$ & $\begin{array}{l}\text { Post } \\
\text { operative }\end{array}$ & $\begin{array}{l}\text { Pre } \\
\text { operative }\end{array}$ & $\begin{array}{l}\text { Post } \\
\text { operative }\end{array}$ \\
\hline $\begin{array}{l}\text { De Silva } \\
\text { (2006) [7] }\end{array}$ & $76.1 \pm 11.4$ & $\begin{array}{l}3.4 \mathrm{~mm} \text { temporal } \\
\text { corneal incision }\end{array}$ & $2.58 \pm 3.14$ & $-0.13 \pm 1.00$ & $0.82 \pm 3.28$ & $-1.07 \pm 0.82$ & $3.52 \pm 1.11$ & $1.23 \pm 0.90$ & $3.08 \pm 0.76$ & $2.90 \pm 1.52$ \\
\hline $\begin{array}{l}\text { Entabi } \\
\text { (2011) [8] }\end{array}$ & $80.6 \pm 8.9$ & $\begin{array}{l}3.2 \mathrm{~mm} \text { steep meridian } \\
\text { corneal incision }\end{array}$ & $1.55 \pm 2.42$ & $0.13 \pm 0.72$ & $-0.13 \pm 2.31$ & $-0.26 \pm 0.62$ & $3.35 \pm 1.20$ & $0.95 \pm 0.66$ & $2.94 \pm 0.89$ & $2.42 \pm 1.38$ \\
\hline $\begin{array}{l}\text { Kersey } \\
(2007)[9]\end{array}$ & 62 & $\begin{array}{l}2.7 \mathrm{~mm} \text { clear corneal } \\
\text { temporal incision }\end{array}$ & - & - & - & -0.36 & 7.36 & - & $10.12 \pm 5.60$ & $2.27 \pm 1.14$ \\
\hline $\begin{array}{l}\text { Kim } \\
(2010)[10]\end{array}$ & $55.8 \pm 16.2$ & $\begin{array}{l}2.2 \mathrm{~mm} \text { temporal clear } \\
\text { corneal incision }\end{array}$ & $-1.88 \pm 3.58$ & - & $19.8 \pm 2.10$ & - & $1.28 \pm 0.72$ & $0.28 \pm 0.21$ & $\begin{array}{l}\text { Manual keratometer } \\
1.57 \pm 0.51 \text { Optical } \\
\text { coherence biometry } \\
\text { (IOL master) } 1.63 \pm 0.43 \\
\text { Scheimpflug SimKs } \\
\text { (Pentacam) } 1.67 \pm 0.60\end{array}$ & - \\
\hline $\begin{array}{l}\text { Koshy } \\
\text { (2010) [11] }\end{array}$ & 71.5 & $\begin{array}{l}3.0 \mathrm{~mm} \text { temporal } \\
\text { self-sealing incision }\end{array}$ & - & - & - & - & - & - & $\begin{array}{l}\text { Partial coherence } \\
\text { interferometry } \\
1.97 \pm 0.58 \\
\text { Scheimpflug SimKs } \\
\text { (Pentacam) } \\
-1.84 \pm 0.79\end{array}$ & $-0.84 \pm 0.41$ \\
\hline $\begin{array}{l}\text { Lane } \\
\text { (2009) [12] }\end{array}$ & $69.1 \pm 11.9$ & $3.0 \mathrm{~mm}$ temporal incision & - & - & - & - & - & - & - & - \\
\hline $\begin{array}{l}\text { Leyland } \\
\text { (2001) [13] }\end{array}$ & 77 & $3.0 \mathrm{~mm}$ temporal incision & - & - & - & - & $3.2 \pm 1.1$ & $0.85 \pm 0.66$ & - & - \\
\hline $\begin{array}{l}\text { Mendicute } \\
\text { (2009) [14] }\end{array}$ & $69.3 \pm 8.2$ & $\begin{array}{l}2.75 \mathrm{~mm} \text { temporal } \\
\text { corneal incision }\end{array}$ & $0.88 \pm 1.80$ & $0.71 \pm 1.85$ & - & - & $-1.75 \pm 0.71$ & $-0.62 \pm 0.46$ & - & - \\
\hline $\begin{array}{l}\text { Mendicute } \\
\text { (2008) [15] }\end{array}$ & $72.1 \pm 8.2$ & $\begin{array}{l}2.75 \mathrm{~mm} \text { temporal } \\
\text { corneal incision }\end{array}$ & $1.26 \pm 1.85$ & $-0.12 \pm 0.44$ & - & - & $-2.34 \pm 1.28$ & $-0.72 \pm 0.43$ & - & - \\
\hline $\begin{array}{l}\text { Mingo-Botin } \\
\text { (2010) [16] }\end{array}$ & $71.5 \pm 11.1$ & $\begin{array}{l}2.8 \mathrm{~mm} \text { corneal incision } \\
\text { (temporal for right eye; } \\
\text { nasal for left eye) }\end{array}$ & $-0.40 \pm 1.89$ & $0.20 \pm 0.33$ & $-0.21 \pm 0.12$ & - & $-1.89 \pm 0.57$ & $-0.61 \pm 0.41$ & $1.73 \pm 0.38$ & $1.87 \pm 0.66$ \\
\hline $\begin{array}{l}\text { Ruhswurm } \\
\text { (2000) [17] }\end{array}$ & $75 \pm 9$ & $\begin{array}{l}3.0-3.2 \mathrm{~mm} \text { clear corneal } \\
\text { self-sealing incision }\end{array}$ & - & - & - & - & $2.68 \pm 0.93$ & $0.84 \pm 0.63$ & $2.7 \pm 0.88$ & $2.3 \pm 0.80$ \\
\hline
\end{tabular}




\begin{tabular}{|c|c|c|c|}
\hline Authors & Surgically inducted astigmatism & Rotational Stability & $2^{\text {nd }}$ surgery needed \\
\hline De Silva (2006) [7] & Not reported & 5 degrees (range: $0-15$ ) & 1 \\
\hline Entabi (2011) [8] & $-2.95 \pm 1.34$ & 3.4 degrees (range: 1-12) & 1 \\
\hline Kersey (2007) [9] & Not reported & 5.33 degrees (range: 0-9) & NR \\
\hline Kim (2010) [10] & Not reported & 3.45 degrees (range: $0-10.3$ ) & 0 \\
\hline Koshy (2010) [11] & Not reported & 2.66 degrees(range: $0-7.6$ ) & NR \\
\hline Lane (2009) [12] & Not reported & NR & NR \\
\hline Leyland (2001) [13] & $0.79(0.22)^{*}$ & 8.9 degrees (range: $0-40$ ) & NR \\
\hline Mendicute (2009) [14] & $J 0=100 \%$ within $\pm 1.0 \mathrm{D} ; J 45=100 \%$ within $\pm 0.5 \mathrm{D}$ & 3.53 degrees (range:0-8) & 0 \\
\hline Mendicute (2008) [15] & $J 0=100 \%$ within $\pm 1.0 \mathrm{D} ; J 45=100 \%$ within $\pm 1.0 \mathrm{D}$ & 3.63 degrees (range: $0-12$ ) & 0 \\
\hline Mingo-Botin (2010) [16] & $\begin{array}{l}J 0=100 \% \text { within } \pm 0.5 \mathrm{D} ; J 45=90 \% \\
\text { within } \pm 0.5 \mathrm{D} ; \mathrm{M}=90 \% \text { within } \pm 0.5 \mathrm{D}\end{array}$ & 3.65 (range: $0-10$ ) & 0 \\
\hline Ruhswurm (2000) [17] & $78.4 \%$ within $\pm 1.0 \mathrm{D} ; 48.6 \%$ within $\pm 0.5 \mathrm{D}$ & $100 \%>25$ degrees & NR \\
\hline
\end{tabular}

\section{Review restrictions}

The systematic review was restricted to a cataract population with astigmatism, treated with toric lens, and with the outcome, uncorrected visual acuity, reported.

Studies that did not specify a cataract population were assumed to be a mixed patient population (cataract patients and refractive lens exchange), and excluded from the review.

Either uncorrected or best corrected visual acuity can be used to measure improvements in VA. While the WHO may define visual impairment and blindness according to visual acuity with "best possible correction", evidence suggests that uncorrected visual acuity has a significant impact on vision-related quality of life $[19,20]$. Before quality of life improvements caused by toric IOLs in astigmatic cataract patients are assessed, it is necessary to demonstrate the efficacy of toric IOLs.

The measurement unit of uncorrected visual acuity varies across many studies. The Snellen scale, Jaeger scale, the decimal of the Snellen scale and the logarithm of the minimum angle of resolution (LogMAR) are the most commonly used units of measurement [21]. Converting these units into a standardized unit has statistical challenges where individual (patient) level data is not available [21]. Published literature exists to suggest that transforming group-level mean and standard deviation of VA across different levels of measurement is possible [21]. But to transform group-level data, a 'reasonable size' patient population $(\mathrm{N} \geq 30)$ is needed [21].

Studies that did not report the outcomes of the full population were not included, and excluded on the basis of incomplete data.

\section{Discussion}

Our study compared uncorrected visual acuity, measured both at near, intermediate and distant ranges. The results of studies identified through this systematic review showed improvements in UDVA. Prior to this study, there have been no known evaluations comparing studies measuring outcomes in toric intraocular lens. This study shows the collective improvement of distant visual acuity.

Toric IOLs have a two-function purpose. The first is to restore visual acuity deteriorated by cataract of the eye. The second function of the toric IOL is to correct corneal astigmatism, thereby restoring vision to a level close to normal, where spectacles are no longer needed. Hence, the authors argue that uncorrected visual acuity, as an outcome measure, is more important than best corrected visual acuity when measuring the efficacy of toric IOLs. A final outcome to be included (not included in this analysis) would be whether patients become spectacle independent, and the impact this has on the quality of life of the patient population.

The outcomes of this systematic review showed significant improvements in uncorrected distant visual acuity. While only a half of the studies (5/11) reported pre- and post-operative values, the outcomes of trials only reporting post-operative values were similar to the postoperative results in the studies that reported pre- and post operative values. The trials that were identified in the systematic search, only one reported QoL, and spectacle independence [16]. Using the VF-14 instrument to measure QoL, patient satisfaction increased from 60.13 $( \pm 17.14)$ to $90.73( \pm 11.07)$. Spectacle independence decreased for patients treated with toric IOLs from $40 \%$ (who always used spectacles) to $0 \%$ (who always used 
spectacles). Patients who occasionally wore spectacles decreased from $20 \%$ to $10 \%$ and patients who frequently wore spectacles decreased from $30 \%$ to $5 \%$. Patients that never wore spectacles increased from $15 \%$ to $85 \%$.

\section{Conclusions}

This systematic review has provided evidence to support the hypothesis that toric IOLs increase the uncorrected distant visual acuity in cataract patients. A major issue with the supporting evidence is the lack of consistency among studies reporting toric IOL outcomes. Uncorrected visual acuity is one of the many possible outcomes that can be used to measure the efficacy of toric IOLs, and there have been many studies reporting variations in methods of reporting such results. Mean visual acuity after cataract surgery is the most commonly reported method, while proportions of patients achieving a minimum visual acuity level have been another highly reported method. Unfortunately, few studies have been published that report UDVA using toric lens in a cataract population with astigmatism, and no studies were identified that reported either UIVA or UNVA. Challenges exist in comparing this proportional method of reporting with other studies.

\section{Additional file}

Additional file 1: Appendix A Search string.

\section{Abbreviations}

IOL, Intraocular lenses; NHS, National Health Service; NR, Not reported QoL, Quality of life; QUORUM, Quality of reporting of meta-analyses; UDVA, Uncorrected distance visual acuity; UIVA, Uncorrected intermediate visual acuity; UK, United Kingdom; UNVA, Uncorrected near visual acuity; VA, Visual acuity.

\section{Competing interests}

Blaise Agresta and Christina Donatti were paid consultants to Alcon Laboratories, Inc. and employees of IMS Health. Daniel Jackson is an employee of Alcon Laboratories, Inc. Michael C. Knorz is a consultant to Alcon.

\section{Authors' contributions}

BA participated in the design and review of the systematic review, managed the data collection and was involved with the manuscript development. CD and DJ provided technical expertise for the analysis and interpretation of the data and were involved with the manuscript development. MK provided clinical expertise and approved the final version of the manuscript. All authors read and approved the final manuscript.

Received: 6 February 2012 Accepted: 4 July 2012

Published: 15 August 2012

\section{References}

1. Olver J, Cassidy L: Ophthalmology at a Glance. Chichester: John Wiley and Sons Ltd; 2005.

2. Reidy A, Minassian DC, Vafidis G, Joseph J, Farrow S, Wu J, et al: Prevalence of serious eye disease and visual impairment in a north London population: population based, cross sectional study. BMJ 1998, 316:1643-1646.

3. Minassian DC, Reidy A, Desai P, Farrow S, Vafidis G, Minassian A: The deficit in cataract surgery in England and Wales and the escalating problem of visual impairment: epidemiological modelling of the population dynamics of cataract. Br J Ophthalmol 2000, 84:4-8.

4. Read SA, Collins MJ, Carney LG: A review of astigmatism and its possible genesis. Clin Exp Optom 2007, 90:5-19.

5. Desai P, Reidy A, Minassian DC, Vafidis G, Bolger J: Gains from cataract surgery: visual function and quality of life. Br J Ophthalmol 1996, 80:868-873.

6. Savage $H$, Rothstein M, Davuluri G, El GL, Zaetta DM: Myopic astigmatism and presbyopia trial. Am J Ophthalmol 2003, 135:628-632.

7. De Silva DJ, Ramkissoon YD, Bloom PA: Evaluation of a toric intraocular lens with a Z-haptic. J Cataract Refract Surg 2006, 32:1492-1498.

8. Entabi M, Harman F, Lee N, Bloom PA: Injectable 1-piece hydrophilic acrylic toric intraocular lens for cataract surgery: efficacy and stability. J Cataract Refract Surg 2011, 37:235-240.

9. Kersey JP, O'Donnell A, Illingworth CD: Cataract surgery with toric intraocular lenses can optimize uncorrected postoperative visual acuity in patients with marked corneal astigmatism. Cornea 2007, 26:133-135.

10. Kim MH, Chung TY, Chung ES: Long-term efficacy and rotational stability of AcrySof toric intraocular lens implantation in cataract surgery. Korean J Ophthalmol 2010, 24:207-212

11. Koshy JJ, Nishi Y, Hirnschall N, Crnej A, Gangwani V, Maurino V, et al: Rotational stability of a single-piece toric acrylic intraocular lens. J Cataract Refract Surg 2010, 36:1665-1670.

12. Lane SS, Ernest P, Miller KM, Hileman KS, Harris B, Waycaster CR: Comparison of clinical and patient-reported outcomes with bilateral AcrySof toric or spherical control intraocular lenses. J Refract Surg 2009, 25:899-901.

13. Leyland M, Zinicola E, Bloom $\mathrm{P}$, Lee $\mathrm{N}$ : Prospective evaluation of a plate haptic toric intraocular lens. Eye 2001, 15:2-5.

14. Mendicute J, Irigoyen C, Ruiz M, Illarramendi I, Ferrer-Blasco T, Montes-Mico R: Toric intraocular lens versus opposite clear corneal incisions to correct astigmatism in eyes having cataract surgery. J Cataract Refract Surg 2009, 35:451-458.

15. Mendicute J, Irigoyen C, Aramberri J, Ondarra A, Montes-Mico R: Foldable toric intraocular lens for astigmatism correction in cataract patients. J Cataract Refract Surg 2008, 34:601-607.

16. Mingo-Botin D, Munoz-Negrete FJ, Won Kim HR, Morcillo-Laiz R, Rebolleda G, Oblanca N: Comparison of toric intraocular lenses and peripheral corneal relaxing incisions to treat astigmatism during cataract surgery. J Cataract Refract Surg 2010, 36:1700-1708.

17. Ruhswurm I, Scholz U, Zehetmayer M, Hanselmayer G, Vass C, Skorpik C: Astigmatism correction with a foldable toric intraocular lens in cataract patients. J Cataract Refract Surg 2000, 26:1022-1027.

18. OCEBM Levels of Evidence Working Group: The Oxford 2011 Levels of Evidence. Oxford Centre for Evidence-Based Medicine. 2012. Ref Type: Electronic Citation

19. World Health Organization: International statistical classification of diseases, injuries and causes of death. 10th edition. Geneva: WHO; 1993.

20. Bourne RR: Uncorrected refractive error and presbyopia: accommodating the unmet need. Br J Ophthalmol 2007, 91:848-850.

21. Khoshnood B, Mesbah M, Jeanbat V, Lafuma A, Berdeaux G: Transforming scales of measurement of visual acuity at the group level. Ophthalmic Physiol Opt 2010, 30:816-823.

doi:10.1186/1471-2415-12-41

Cite this article as: Agresta et al:: Visual acuity improvements after implantation of toric intraocular lenses in cataract patients with astigmatism: a systematic review. BMC Ophthalmology 2012 12:41. 